\title{
Preclinical syndromes predict dementia: the Sydney older persons study
}

\author{
L M Waite, G A Broe, D A Grayson, H Creasey
}

\begin{abstract}
Objectives-To identify if preclinical syndromes for Alzheimer's disease, vascular dementia, and Parkinson's disease and related dementias exist. Identification of dementia at early or even preclinical stages has important implications for treatment.

Methods-A community dwelling sample of 647 subjects aged 75 and over at recruitment were followed up for a mean period of 3.19 years (range 2.61 to 4.51 years). Each subject was asked to participate in a medical assessment which included a standardised medical history examining both past and current health and medication usage; a neuropsychological battery (mini mental state examination, Reid memory test, verbal fluency, subsets of the Boston naming test and similarities, clock drawing and copied drawings) and physical examination. Preclinical syndromes for the three predominant dementias (Alzheimer's disease, vascular dementia and Parkinson's disease, and related dementias) and their combinations were defined using cognitive, motor, and vascular features. Their longitudinal outcome as defined by death and dementia incidence was examined.
\end{abstract}

Results-Preclinical syndromes affected $55.7 \%(n=299)$ of subjects. Preclinical syndromes showed a trend for an increased odds of death (odds ratio $1.72, p=0.056$ ) and a significantly increased odds of developing dementia (odds ratio 4.81, p<0.001). Preclinical syndromes were highly sensitive, detecting 52 of $58(89.7 \%)$ incident dementias. Two hundred and sixteen of $268(80.6 \%)$ preclinical subjects did not show dementia over the 3 year period (positive predictive value $19.4 \%$ ). Subjects defined as having a combination of cognitive, extrapyramidal, and vascular features were at greatest risk of progressing to dementia.

Conclusions-Preclinical syndromes were sensitive and significant predictors of dementia. In view of their poor positive predictive value, the preclinical syndromes as defined in this study remain a research tool needing both definitional refinement and greater periods of observation. Multiple coexistent preclinical disorders resulted in a greater incidence of dementia, providing evidence for an additive role between multiple disorders. (F Neurol Neurosurg Psychiatry 2001;71:296-302)

Keywords: dementia; Alzheimer's disease
Epidemiological and neuropathological series have identified Alzheimer's disease, vascular dementia, and dementia associated with Lewy bodies as the three predominant dementing processes. $^{1-4}$ Dementia in association with Lewy bodies has not been well recognised in epidemiological studies, perhaps as a result of its clinical heterogeneity and, until recently, the lack of uniform diagnostic criteria. In view of the numerous terminologies this group will be called Parkinson's disease and related dementias (PDRD) in this paper in an attempt to capture the range of patients hypothesised to have both Lewy bodies and dementia.

Clinical and epidemiological evidence generally supports the presence of a cognitive continuum and a preclinical phase to dementia, particularly Alzheimer's disease. Identification of syndromes that will progress to dementia and the different dementia subtypes carries immense importance for the management of these diseases when therapies are available and for future research into effective early prevention. The focus of most studies to date has been Alzheimer's disease where neuropsychological, ${ }^{5-8}$ radiological, ${ }^{9-11}$ and neuropathological ${ }^{12-14}$ predictors of incident Alzheimer's disease have been identified. It is likely that dementia associated with Lewy bodies, a neurodegenerative disorder with risk factors overlapping those of Alzheimer's disease, would also occur along a continuum. The presence of mild cognitive deficits in nondemented subjects with Parkinson's disease ${ }^{15} 16$ would lend support to this. Vascular dementia may have an abrupt onset after a stroke and it could be argued that it would be a good candidate for the dichotomous disease model, with no preclinical phase. However, mild neuropsychological deficits are well recognised with white matter disease $\mathrm{e}^{17-19}$ and a clinically significant stroke may be on a continuum with small vessel disease or leukoaraiosis. Thus, when examining the continuum hypothesis it is important to consider the potential preclinical disorders that may progress to the three predominant dementias-Alzheimer's disease, vascular dementia, and PDRD. Each will have different clinical, neuropsychological, and radiological presentations and different responses to treatment. Furthermore, as in dementia, mixed preclinical syndromes may exist, particularly in older populations.

Suitable criteria defining the preclinical state for the three predominant dementias and their combinations do not exist. Much of the research has been done on selected populations and as noted, has largely focused on 
Alzheimer's disease, ignoring vascular dementia, PDRD, and mixed disorders. This paper aims to examine the hypothesis in a community population that not only does a preclinical phase to dementia exist but that preclinical states for the three major dementias can be identified. Preclinical syndromes for Alzheimer's disease, vascular dementia, and PDRD will be defined and their longitudinal outcomes, including both dementia and death, examined.

\section{Methods}

STUDY POPULATION

A sample of 647 non-institutionalised men and women aged 75 years or older residing in the Central Sydney Area Health Service participated in the Sydney Older Persons Study from 1991 to $1994 .^{20}{ }^{21}$ The sample consisted of two groups; randomly selected war veterans and war widows from a war veterans/widows listing in the same local area $(n=327$, response rate $82 \%$ ) and non-veterans derived from a local area probability sampling scheme $(n=320$, response rate $73 \%$ ). Men were in excess in the veteran sample, comprising $59.3 \%$ versus $39.7 \%$ of the community. Veteran and community subjects were compared across a range of variables examining demographic, lifestyle, psychological, functional, medical, and related factors to ascertain if they differed in significant ways. No significant differences were identified. Thus, rather than treating veteran and community subjects differently throughout the study data are pooled.

Of the 647 subjects at time 1537 participated in a medical assessment which included a standardised medical history examining past and current health and medication usage; a neuropsychological battery, and physical examination. The neuropsychological battery aimed to examine the following areas of cognition: memory, language, visuospatial function, and frontal and executive function. The neuropsychological battery consisted of well validated tests and included the mini mental state examination $(\mathrm{MMSE})^{22}$; Reid memory test ${ }^{23}$; tests of verbal fluency $\left(\mathrm{F}, \mathrm{A}\right.$, and $\mathrm{S},{ }^{24}$ and animals ${ }^{25}$ ); subsets of the Boston naming test ${ }^{26}$ and similarities ${ }^{27}$; clock drawing ${ }^{28}$ and copied drawings of a cube, coils, and interlocking infinity loops. ${ }^{29}$ Subjects not participating in the medical assessment at time 1 showed no significant differences in age, disability, number of falls, and MMSE scores. ${ }^{21}$ Subjects were reassessed after a mean period of 3.19 years (range 2.61 to 4.51 years (SD 0.21 )). Of the original 647 subjects, some information was available on over $95 \%$ at time 2 . Time 1 and time 2 data indicated that those who died $(n=128,19.8 \%$ of the original 647$)$ were sicker, older, more cognitively impaired, and more likely to be men. Time 2 refusals and non-contacts did not differ in age, MMSE score, number of drugs, number of falls, or disability as measured at time 1 . At both assessments subjects gave written informed consent and the study had institutional ethics approval.
DEFINING THE PRECLINICAL SYNDROMES Preclinical syndromes for the three main dementias (Alzheimer's disease, vascular dementia, and PDRD) both singly and in combination were defined. It was necessary to define multipathological preclinical syndromes as $34 \%$ of patients with dementia were found to be multiaetiological at time $1 .^{21} \mathrm{With}$ respect to vascular and extrapyramidal features the disorders may be present initially without evidence of cognitive deficits. We defined distinct sets of preclinical syndromes for vascular dementia and PDRD where cognitive deficits were either present or absent.

Subjects hypothesised as having preclinical Alzheimer's disease were defined as having cognitive impairment without either vascular or extrapyramidal features.

Vascular dementia is characterised by dementia with historical or clinical evidence of stroke ${ }^{3031}$ in association with possible evidence of $\operatorname{cardiac}^{31}{ }^{32}$ and peripheral vascular disease $^{3334}$ and the presence of vascular risk factors such as atrial fibrillation, hypertension, hypercholesterolaemia, diabetes, and smoking. ${ }^{30} 3135$ At a predementia syndromal level any of these characteristics may be expected. Cognitive deficits at a preclinical level will depend on the site and severity of the cerebrovascular disease $^{36}$ and may be absent. The "cognitive impairment plus prevascular" group included those with vascular features in combination with cognitive deficits whereas the "prevascular" group had no cognitive deficits.

Parkinson's disease and related dementias is characterised by dementia in association with prominent extrapyramidal (EP) features including bradykinesia, rigidity, and tremor. At a predementia level such abnormalities, of lesser severity, would be expected to occur in association with varying levels of cognitive deficits. The extrapyramidal groups are termed "preEP" and "cognitive impairment plus pre-EP".

As both vascular and extrapyramidal features may coexist, two groups termed "prevascular plus pre-EP" and "cognitive impairment plus prevascular plus pre-EP" were also created. Thus a total of seven preclinical groups were created and the features of each of these is summarised in table 1 .

There are three delineating features which characterise the seven preclinical groups; the presence of cognitive deficits, vascular features, and extrapyramidal features. Scales measuring these three concepts were defined.

Table 1 Predementia syndromes

\begin{tabular}{llll}
\hline Syndrome & $\begin{array}{l}\text { Cognitive } \\
\text { impairment }\end{array}$ & $\begin{array}{l}\text { Vascular } \\
\text { features }\end{array}$ & $\begin{array}{l}\text { Extrapyramidal } \\
\text { features }\end{array}$ \\
\hline Normal & - & - & - \\
CI & + & - & - \\
Prevascular & - & + & - \\
CI+prevascular & + & + & - \\
Pre-EP & - & - & + \\
CI+pre-EP & + & - & + \\
Prevascular+pre-EP & - & + & + \\
CI+prevascular+pre-EP & + & + & +
\end{tabular}

$\mathrm{CI}=$ Cognitive impairment; pre-EP=preclincal extrapyramidal. 
Cognitive impairment

Subjects were clinically defined as having cognitive impairment if the subject did not reach DSM-III-R criteria $^{37}$ for dementia and displayed mild to moderate deficits in one or more areas of cognition (memory, language, visuospatial, or executive function). Subjects did not display significant functional impairment as a direct consequence of their cognitive deficits. Weekly meetings attended by the examining physician, senior neurologists, and a neuropsychologist were held. Each assessment was reviewed and discussed to maintain diagnostic consistency. All information from the medical assessment and neuropsychological battery was used in the assignation of a diagnosis of cognitive impairment.

\section{Vascular features}

Two equally weighted components were defined. The first of these was an arteriopathy score. This score measured evidence of noncerebral vascular disease in addition to vascular risk. Its components included atrial fibrillation, diabetes, hypertension, heart disease, claudication, self reported hypercholesterolaemia, and smoking history. The first six of these (scored dichotomously) were derived from International Classification of Diseases (ICD)-9 diagnoses assigned by a physician (HC) after review of the clinical assessment notes and diagnostic summaries. Smoking history (scored continuously from zero for lifetime non-smokers to one for the maximum smoking in the study population) was derived from self reports. Each component was scored out of 1 and was summed to create the arteriopathy score (maximum score 7 ). The mean arteriopathy score was 1.51 in non-demented subjects and 2.47 in subjects with vascular dementia, which was significantly different $(p=0.000)$. No other dementia subgroups had an arteriopathy score that was significantly different from normal subjects. Thus a conservative cut off of three or more in the arteriopathy score was employed.

The second component of the vascular score measured evidence of cerebrovascular disease. International Classification of Diseases-9 diagnoses of transient ischaemic attacks and stroke were derived from the medical history and examination. Subjects met the prevascular criterion if they had either an arteriopathy score greater than or equal to three or an ICD-9 diagnosis of transient ischaemic attack, or stroke, or both of these.

\section{Extrapyramidal features}

Two components comprised the extrapyramidal measure. The first component was an extrapyramidal score (EP score) and the second an objective measure of extrapyramidal gait disorder. The EP score included measures of tone (rigidity, cogwheeling, nuchal rigidity), bradykinesia (slowed fine finger movements, reduced arm swing, and an overall clinical assessment of the presence of bradykinesia), resting tremor, postural flexion, and the glabella tap. Each of theses features was graded as zero absent; 0.33 mild; 0.66 moderate; 1 severe. A relatively conservative cut off of one or more in the EP score was used corresponding to either one severe sign, one moderate and one mild sign, or three mild signs. This cut off was therefore stricter than that employed in previous studies. ${ }^{38}$

The second component of the algorithm defining the pre-EP syndrome was an objective measure of extrapyramidal gait changes as assessed by the time to complete a 5 metre returned walk. In this study population $71 \%$ had a diagnosis of arthritis. ${ }^{21}$ Two procedures were employed to identify a time indicative of extrapyramidal slowing. The first of these was to adjust the timed walk for arthritis. Measures of functional severity of arthritis in both right and left hips and knees were summed to give a total lower limb arthritis score out of four. The timed walk was then adjusted for arthritis using a linear regression model. The second procedure employed was to find a "normal" timed walk. A group of normal subjects was defined as those subjects who did not have any of the following diagnoses: Parkinson's disease, stroke, dementia, lower limb arthritis, or the presence of ataxia as measured by greater than one step out of line or marked sway over 10 steps of tandem gait; 168 subjects fulfilled these criteria. Their mean timed walk was 12.55 seconds with an SD of about 4.50 seconds. A cut off point of the mean plus 2 SD for the adjusted timed walk, free of arthritis, was used to identify abnormal slowing. Thus, those subjects who had an adjusted timed walk of greater than 21.55 seconds were included in the extrapyramidal prodromal group.

\section{DEMENTIA DIAGNOSES}

Diagnoses of dementia made by a physician at time 1 fulfilled DSM-III-R criteria. ${ }^{37}$ Dementia diagnoses were made at the completion of the medical assessment using all information from the medical assessment and neuropsychological battery. Weekly meetings reviewing each assessment were attended by the examining physician, senior neurologists, and a neuropsychologist to maintain diagnostic consistency. The medical assessment at time 2 reflected that done at time 1 and diagnoses of dementia fulfilled the general DSM IV criteria (criteria A and B) ${ }^{39}$ Limited data are available indicating how the use of different diagnostic criteria may affect disease estimates. In available studies DSM IV may diagnose slightly fewer subjects as demented although the differences are small and further studies to verify these findings are required. ${ }^{40}{ }^{41}$ In this study it was not possible to retrospectively apply either DSM IV criteria to time 1 data or DSM-III-R criteria to time 2 data and it is therefore not known how the use of different diagnostic criteria over the two waves may affect the results. However, to the extent that DSM-III-R may be more inclusive in the diagnosis of dementia, DSM IV dementia incidence at time 2 is based on a more unambiguously dementia free time 1 cohort.

A total of 308 subjects who were not demented at time 1 had two waves of medical data (fig 1). Among those who died before time 2 or did not have a medical assessment at time 


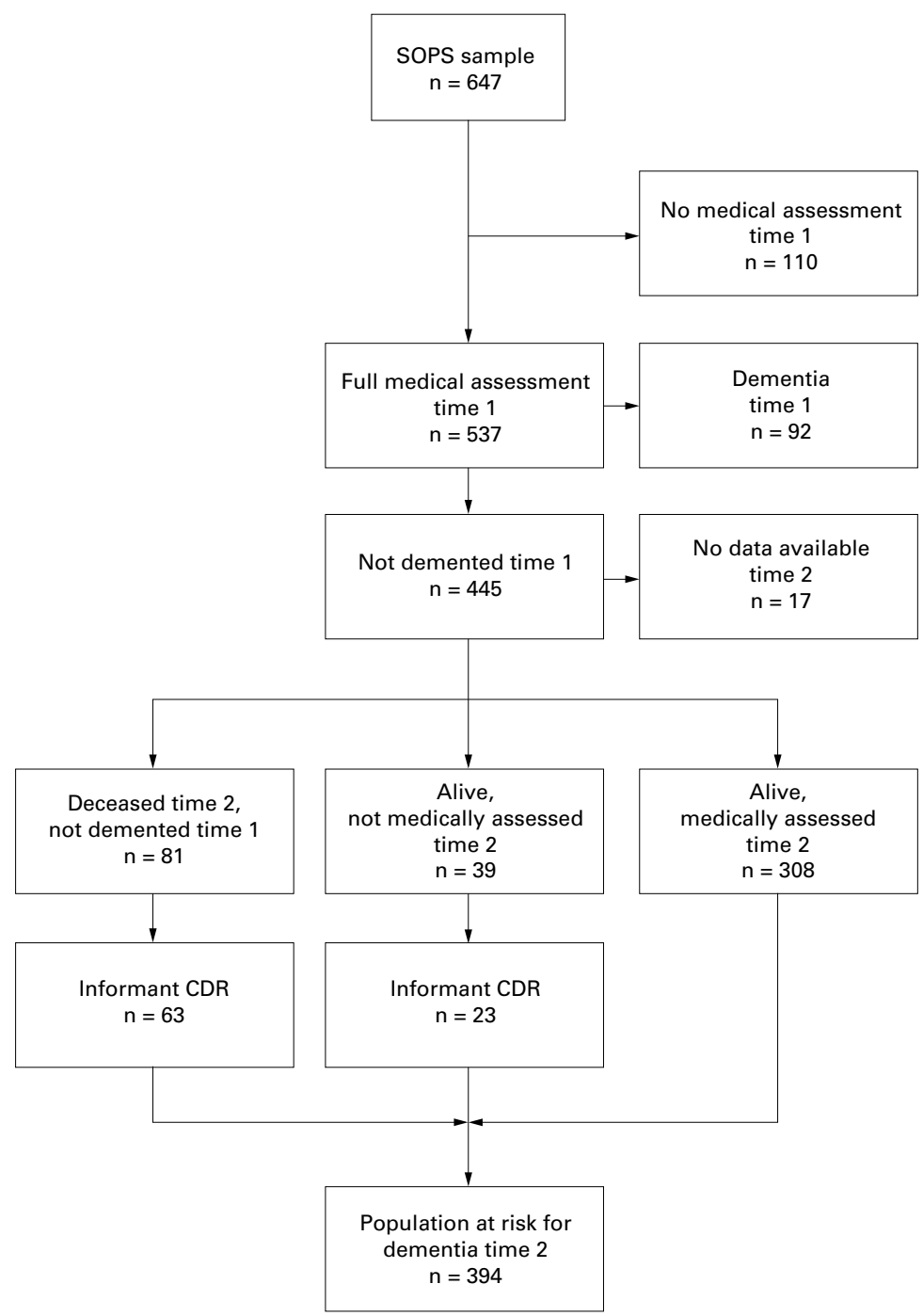

Figure 1 Flow diagram of the study population. $C D R=$ clinical dementia rating.

$2(n=120)$ an informant questionnaire ${ }^{42}$ which examined the six domains of the clinical dementia rating $(C D R)$ was used $(n=86)$ to identify incident dementia cases in order to achieve more complete case ascertainment (sensitivity $80 \%$, specificity $98 \%$ ). A common problem in studies on the incidence of dementia is the lack of data on subjects who die between the two waves of assessment or have incomplete testing. In removing such subjects from analyses it is presumed that they did not become cases of incident dementia. In this study a validated informant questionnaire which has been found to have moderate agreement with clinician based CDR ratings ${ }^{42}$ was used, thereby achieving more complete case ascertainment. Subjects assessed by the informant questionnaire were diagnosed as demented if they were rated as mildly, moderately, or severely demented according to the informant CDR.

STATISTICAL ANALYSIS

Non-demented subjects who participated in a medical assessment at time 1 were defined as being either preclinical or well. Using well subjects as the reference group, a logistic regression model examined whether the preclinical syndromes (both as a group and as individual syndromes) were predictive of either death or dementia.

\section{Results}

The prevalence of the preclinical syndromes at time 1 is shown in table 2. Preclinical syndromes constituted 299 of 537 (55.7\%) study subjects.

To display baseline functioning of the preclinical subjects, table 3 shows the mean MMSE scores of well, preclinical, and demented subjects at time 1 . The final column in the table indicates whether the group had a significantly different MMSE score from well subjects. All subjects with a cognitive impairment component had a significantly different MMSE score when compared with well subjects.

Data were available on 428 subjects for mortality at time 2 (fig $1 ; 81$ subjects who were not demented at time 1 but were known to be deceased at time 2, 39 alive but not medically assessed at time 2, and 308 medically assessed at time 2). The odds of any preclinical syndrome resulting in death was $1.72(95 \%$ confidence interval (95\% CI) 0.99-3.01, $\mathrm{p}=0.056)$. The odds of each preclinical syndrome resulting in death are shown in table 4.

Data were available on 394 subjects at time 2 for dementia status (fig 1). The odds of any preclinical syndrome resulting in dementia was 4.81 (95\% CI 2.01-11.51, $\mathrm{p}<0.001)$. The odds of each preclinical syndrome resulting in dementia are shown in table 5. With the exception of the prevascular and pre-EP groups all preclinical syndromes were at greater risk of progressing to dementia over the 3 year period. The risk was maximal in the cognitive impairment plus prevascular plus pre-EP group.

Of the 58 incident dementias, $52(89.7 \%)$ arose from the preclinical groups (negative

Table 2 Time 1 prevalence of the well subjects and preclinical syndromes

\begin{tabular}{lc}
\hline Subgroup & Prevalence $(n(\%))$ \\
\hline Normal subjects & $146(32.8)$ \\
CI & $77(17.3)$ \\
Prevascular & $55(12.4)$ \\
CI+prevascular & $25(5.4)$ \\
Pre-EP & $45(10.1)$ \\
CI+pre-EP & $42(9.4)$ \\
Prevascular+pre-EP & $31(7.0)$ \\
CI+pre-vascular+pre-EP & $24(5.4)$ \\
Total & $445(100)$
\end{tabular}

$\mathrm{CI}=$ Cognitive impairment; Pre-EP=preclincal extrapyramidal.

Table 3 Mean MMSE scores for well, preclinical, and demented subjects at Time 1

\begin{tabular}{lll}
\hline Subgroup & $\begin{array}{l}\text { Mean } \\
\text { MMSE score }\end{array}$ & $\begin{array}{l}\text { Different from } \\
\text { well subjects }(p)\end{array}$ \\
\hline Well & 27.7 & $\star$ \\
CI & 25.4 & 0.000 \\
Prevascular & 27.7 & 0.984 \\
CI+prevascular & 25.2 & 0.000 \\
Pre-EP & 27.5 & 0.767 \\
CI+pre-EP & 24.7 & 0.000 \\
Prevascular+pre-EP & 27.1 & 0.329 \\
CI+prevascular+pre-EP & 25.9 & 0.004 \\
Demented & 22.2 & 0.000
\end{tabular}

${ }^{\star}$ Reference group.

$\mathrm{CI}=$ Cognitive impairment; Pre-EP=preclincal extrapyramidal. 
Table 4 Odds of death for well and preclinical subgroups

\begin{tabular}{lcclc}
\hline Diagnosis time 1 & $\begin{array}{l}\text { Alive time } 2 \\
(n(\%)\end{array}$ & $\begin{array}{l}\text { Deceased time } 2 \\
(n(\%)\end{array}$ & $\begin{array}{l}\text { Odds ratio } \\
(95 \% \text { CI })\end{array}$ & p Value \\
\hline Well & $120(86.3)$ & $19(13.7)$ & $1^{\star}$ & \\
CI & $62(82.7)$ & $13(17.3)$ & $1.32(0.61-2.86)$ & 0.474 \\
Prevascular & $46(85.2)$ & $8(14.8)$ & $1.10(0.45-2.68)$ & 0.837 \\
CI+prevascular & $20(83.3)$ & $4(16.7)$ & $1.26(0.39-4.10)$ & 0.697 \\
Pre-EP & $31(70.5)$ & $13(29.5)$ & $2.65(1.18-5.94)$ & 0.018 \\
CI+pre-EP & $29(70.7)$ & $12(29.3)$ & $2.61(1.14-5.99)$ & 0.023 \\
Prevascular+pre-EP & $25(86.2)$ & $4(13.8)$ & $1.01(0.32-3.23)$ & 0.986 \\
CI+prevascular+pre-EP & $14(63.6)$ & $8(36.4)$ & $3.61(1.33-9.75)$ & 0.011 \\
\hline
\end{tabular}

${ }^{\star}$ Reference group.

$\mathrm{CI}=$ Cognitive impairment; Pre-EP=preclincal extrapyramidal.

Table 5 Odds of time 1 preclinical syndromes developing incident dementia

\begin{tabular}{lcclll}
\hline & \multicolumn{2}{l}{ Time 2 clinical status $(n(\%))$} & & \\
\cline { 2 - 3 } Preclinical status time 1 & Not demented & Demented & OR $(95 \%$ CI) & p Value \\
\hline Well & $120(95.2)$ & $6(4.8)$ & $1^{\star}$ & \\
CI & $57(79.2)$ & $15(20.8)$ & $5.26(1.94-14.28)$ & 0.001 \\
Prevascular & $48(96.0)$ & $2(4.0)$ & $0.83(0.16-4.27)$ & 0.827 \\
CI+prevascular & $19(79.2)$ & $5(20.8)$ & $5.26(1.46-18.96)$ & 0.011 \\
Pre-EP & $35(87.5)$ & $5(12.5)$ & $2.86(0.82-9.92)$ & 0.098 \\
CI+pre-EP & $23(65.7)$ & $12(34.3)$ & $10.43(3.55-30.63)$ & 0.000 \\
Prevascular+pre-EP & $21(80.8)$ & $5(19.2)$ & $4.76(1.33-17.03)$ & 0.016 \\
CI+prevascular+pre-EP & $13(61.9)$ & $8(38.1)$ & $12.31(3.69-40.99)$ & 0.000 \\
\hline
\end{tabular}

${ }^{\star}$ Reference group.

$\mathrm{CI}=$ Cognitive impairment; Pre-EP=preclinical extrapyramidal

predictive value $95.2 \%$, sensitivity $89.7 \%$ ). Two hundred and sixteen of 268 (80.6\%) preclinical subjects did not show dementia over the 3 year period, indicating a positive predictive value of $19.4 \%$ and specificity of $35.7 \%$ for the preclinical syndromes.

\section{Discussion}

Those fulfilling the criteria for the preclinical syndromes comprised about two thirds $(67.2 \%)$ of the non-demented population and about half $(55.7 \%)$ of the total study population. Direct comparison of this prevalence with other studies is not possible as no other studies have attempted to define preclinical syndromes in this manner. The number of subjects with preclinical syndromes that included cognitive deficits not reaching diagnostic criteria for dementia was 168 - that is, $31.3 \%$ of the 537 subjects examined. Similar figures using nonstandardised criteria for cognitive impairment in the absence of dementia have been identified in other studies. ${ }^{43}{ }^{44}$ Studies employing operationalised criteria have identified prevalences ranging from $34.9 \%{ }^{45}$ to $38.4 \%{ }^{46}$ for age associated memory impairment, $26.6 \%$ for aging associated cognitive decline, ${ }^{47}$ and as low as $4 \%$ for ICD-10 mild cognitive disorder (ICD-10 MCD).$^{48}$ Thus, the clinical criteria in this study yielded far higher prevalences than ICD-10 MCD but similar to those found for age associated memory impairment and aging associated cognitive decline.

Extrapyramidal features were identified in 142 subjects (those with preEP, cognitive impairment plus pre-EP, prevascular plus pre$\mathrm{EP}$, and cognitive impairment plus prevascular plus pre-EP). This represents $31.9 \%$ of the non-demented population. A community study in the United States ${ }^{49}$ found that parkinsonism was present in $29.5 \%$ of all subjects aged 75 to 84 years and in $52.4 \%$ for those 85 years and over. These United States figures were higher than previously reported Italian and Dutch community figures ranging from $3 \%$ to $5.9 \% .^{50}{ }^{51}$ However, different definitions of parkinsonism limit comparability and in community based studies where mild parkinsonism is likely to predominate, small differences in the distinction between the presence or absence of parkinsonism will have a marked impact on prevalence estimates. Thus, bearing in mind definitional issues and our relatively strict criteria, the prevalence of extrapyramidal features in this study is similar to the United States figures but higher than others.

Comparison of the prevalence of vascular features with other studies is not possible as no other studies have employed such a definition.

The increased mortality of the extrapyramidal preclinical syndromes supports previous studies showing that extrapyramidal features have important implications for survival. ${ }^{49}$ The prevascular group had little impact on mortality whereas the extrapyramidal preclinical syndromes seem the most toxic. The trend for increased mortality of the preclinical syndromes provides face and predictive validity for the existence of these groups. However, no direct causal link between the preclinical syndromes and mortality has been identified and they may be acting as a proxy for other, unrecognised risk factors for death.

Of the 58 incident dementias, $52(89.7 \%)$ arose from the preclinical groups (see table 5) providing evidence for their predictive validity and high sensitivity. These findings confirm the hypothesis that preclinical syndromes for dementia exist and the different patterns of progression indicate that preclinical syndromes for the three major dementias are a valid concept. The most likely to progress to dementia were those with all three preclinical components. This supports the summation concept where it is hypothesised that a greater number of disorders reduces the threshold for clinical presentation. The prevascular group was not at increased risk for progression to dementia. This is in keeping with the underlying disease process which, rather than being progressive as the neurodegenerative diseases are, is reliant on the development of further cerebrovascular pathology. A longer period of observation for this group may be required, as noted by Skoog et al. ${ }^{52}$ The rate of dementia progression of the preclinical syndromes is greater than that identified in studies using operationalised criteria including age associated memory impairment ${ }^{354}$ and ICD-10 MCD. ${ }^{55}$ This supports the recent contention that many of these operationalised criteria have definitional limitations and that further consideration and consensus regarding the establishment of appropriate criteria is required. ${ }^{56}$

A poor positive predictive value of $19.4 \%$ was identified for the preclinical syndromes, reflecting that most of those labelled as preclinical did not progress to dementia within a 3 year period. In view of this high false positive rate these syndromes cannot be implemented in a clinical setting but they are a preliminary research tool requiring further refinement in their definition. Possible areas for 
improving their definition include inclusion of neuropsychological tests to allow classification of cognitive impairment according to preclinical Alzheimer's disease, vascular dementia, and PDRD; inclusion of more objective measures of vascular disease such as the presence of carotid artery plaques, carotid wall thickness, and brachial-ankle pressure indices; the inclusion of neuroimaging to identify and quantify cerebral vascular disease, including silent infarction and the inclusion of neuropathological studies, as is awaited in this study. Secondly, the lack of progression may reflect inadequate study duration. Other studies have found a similar lack of progression in those defined as cognitively impaired..$^{57-59}$ The lack of progression early in the disease course may reflect a non-linear rate of decline ${ }^{60}$ where the rate of cognitive decline increases with increasing disease severity. Whether all subjects with preclinical syndromes will eventually progress to dementia requires a far greater period of observation.

In conclusion, the preclinical syndromes were sensitive and significant predictors of dementia, supporting the hypothesis that preclinical syndromes for dementia exist. However, in view of their low positive predictive value they remain a research tool requiring definitional refinement and more prolonged periods of observation. The different rates of progression seen in the preclinical syndromes supports the validity of differentiating the preclinical syndromes. Multiple coexistent preclinical disorders result in a greater incidence of dementia, providing evidence for an additive role between multiple pathologies. Future studies in other community populations, ideally including neuropathological assessment would be of great benefit in further assessing preclinical dementia syndromes.

This study was funded by a grant from the National Health and Medical Research Council. LMW was funded by an $\mathrm{NH}$ and MRC Public Health Research and Development Committee scholarship.

1 Jorm AF, Korten AE, Henderson AS. The prevalence of dementia: a quantitative integration of the literature. Acta Psychiatr Scand 1987;76:465-79.

2 Burns A, Luthert P, Levy R, et al. Accuracy of clinical diagnosis of Alzheimer's disease. BMF 1990;301:1026

3 Hansen L, Salmon D, Galasko D, et al. The Lewy body variant of Alzheimer's disease: a clinical and pathologic entity. Neurology 1990;40:1-8.

4 Perry RH, Irving D, Blessed G, et al. Senile dementia of the Lewy body type: a clinically and neuropathologically distinct form of Lewy body dementia in the elderly. $f$ Neu rol Sci 1990;95:119-39.

5 Linn RT, Wolf PA, Bachman DL, et al. The "preclinical phase" of probable Alzheimer's disease. A 13-year prospective study of the Framingham cohort. Arch Neurol 1995;52: tive study 90 .

6 Crystal HA, Dickson D, Sliwinski M, et al. Associations of status and change measures of neuropsychological function with pathologic changes in elderly, originally nondemented subjects. Arch Neurol 1996;53:82-7.

7 Johansson B, Zarit SH. Early cognitive markers of the incidence of dementia and mortality: a longitudinal population-based study of the oldest old. Int f Geriatr Psychiatry 1997;12:53-9.

8 Rubin EH, Storandt M, Miller JP, et al. A prospective study of cognitive function and onset of dementia in cognitively healthy elders. Arch Neurol 1998;55:395-401.

9 Golomb J, Kluger A, de Leon MJ, et al. Hippocampal formation size predicts declining memory performance in normal aging. Neurology 1996;47:810-3.

10 Haxby JV, Grady CL, Koss E, et al. Longitudinal study of cerebral metabolic asymmetries and associated neuropsychological patterns in early dementia of the Alzheimer type. Arch Neurol 1990;47:753-60.
11 Minoshima S, Giordani B, Berent S, et al. Metabolic reduction in the posterior cingulate cortex in very early tion in the posterior cingulate cortex in very

12 Morris JC, Storandt M, McKeel DW Jr, et al. Cerebral amyloid deposition and diffuse plaques in normal aging: evidence for presymptomatic and very mild Alzheimer's disease. Neurology 1996;46:707-19.

13 Troncoso JC, Martin LJ, Dal Forno G, et al. Neuropathology in controls and demented subjects from the Baltimore longitudinal study of aging. Neurobiol Aging 1996;17:36571

14 Berg L, McKeel Jr DW, Miller JP, et al. Clinicopathologic studies in cognitively healthy aging and Alzheimer's disease. Relation of histopathologic markers to dementia severity, age, sex, and apolipoprotein E genotype. Arch Neverity, age, sex, and $1998 ; 55 ; 326-35$.

15 Reid WG, Hely MA, Morris JGL, et al. A longitudinal study of Parkinson's disease: clinical and neuropsychological correlates of dementia. F Clin Neurosci 1996;3:327-33.

16 Jacobs DM, Marder K, Cote LJ, et al. Neuropsychological characteristics of preclinical dementia in Parkinson's disease. Neurology 1995;45:1691-6.

17 Breteler MM, van Amerongen NM, van Swieten JC, et al. Cognitive correlates of ventricular enlargement and cerebral white matter lesions on magnetic resonance imaging. The Rotterdam Study. Stroke 1994;25:1109-15.

18 Corbett A, Bennett H, Kos S. Cognitive dysfunction following subcortical infarction. Arch Neurol 1994;51:999-1007.

19 Skoog I, Berg S, Johansson B, et al. The influence of white matter lesions on neuropsychological functioning in demented and non-demented 85 year olds. Acta Neurol Scand 1996;93:142-8.

20 Waite LM, Broe GA, Creasey H, et al. Neurological signs, aging, and the neurodegenerative syndromes. Arch Neurol 1996;53:498-502.

21 Waite LM, Broe GA, Creasey H, et al. Neurodegenerative and other chronic disorders among people aged 75 years
and over in the community. Med 7 Aust 1997;167:429-32.

22 Folstein MR, Folstein SE, McHugh PR. Mini-mental state: a practical method for grading the cognitive state of patients for the clinician. $\mathcal{F}$ Psychiatr Res 1975:12:189-98.

23 Reid WG, Broe GA, Creasey H, et al. Age at onset and pattern of neuropsychological impairment in mild early-stage Alzheimer disease. Arch Neurol 1996;53:1056-61.

24 Benton AL, Hamsher K. Multilingual aphasia examination. Iowa City: University of Iowa Press, 1978

25 Goodglass H, Kaplan E. The assessment of aphasia and related disorders. 2nd ed. Philadelphia: Lea and Febiger, 1987.

26 Kaplan E, Goodglass H, Weintraub S. Boston naming test. Philadelphia; Lea and Febiger, 1983.

27 Wechsler D. Wechsler adult intelligence scale-revised. New York: Psychological Corporation, 1981.

28 Strub RL, Black FW. The mental status examination in neurology. Philadelphia: FA Davis, 1988.

29 Lezak MD. Neuropsychological assessment. New York: Oxford University Press, 1995.

30 Yoshitake T, Kiyohara Y, Kato I, et al. Incidence and risk factors of vascular dementia and Alzheimer's disease in a defined elderly Japanese population: the Hisayama study. Neurology 1995;45:1161-8.

31 Rockwood K, Ebly E, Hachinski V, et al. Presence and treatment of vascular risk factors in patients with vascular cognitive impairment. Arch Neurol 1997;54:33-9.

32 Gorelick PB, Brody J, Cohen D, et al. Risk factors for dementia associated with multiple cerebral infarcts. A casecontrol analysis in predominantly African-American hospital-based patients. Arch Neurol 1993;50:714-20.

33 Breteler MMB, Claus JJ, Grobbee DE, et al. Cardiovascular disease and distribution of cognitive function in elderly disease and distribution of cognitive function in elderl
people: the Rotterdam study. BMF 1994;308:1604-8.

34 Phillips NA, Mate-Kole CC. Cognitive deficits in peripheral vascular disease. A comparison of mild stroke patients and normal control subjects. Stroke 1997;28:777-84.

35 Hachinski V, Graffagnino C, Beaudry M, et al. Lipids and stroke: a paradox resolved. Arch Neurol 1996;53:303-8.

36 Tatemichi TK, Desmond DW, Paik M, et al. Clinical determinants of dementia related to stroke. Ann Neurol 1993;33: 568-75.

37 American Psychiatric Association. Diagnostic and statistical manual of mental disorders. 3 rd ed revised. Washington, DC: APA, 1987.

38 Richards M, McLoughlin D, Levy R. The relationship between extrapyramidal signs and cognitive function in patients with moderate to severe Alzheimer's disease. Int $\mathcal{F}$ Geriatr Psychiatry 1995;10:395-9.

39 American Psychiatric Association. Diagnostic and statistical manual of mental disorders. 4th ed. Washington, DC: APA, 1994

40 Erkinjuntti T, Ostbye T, Steenhuis R, et al. The effect of different diagnostic criteria on the prevalence of dementia. $N$ Engl F Med 1997;337:1667-74.

41 Pohjasvaara T, Erkinjuntti T, Vataja R, et al. Dementia three months after stroke. Baseline frequency and effect of different definitions of dementia in the Helsinki stroke aging memory study (SAM) cohort. Stroke 1997;28:785-92.

42 Waite L, Grayson D, Jorm AF, et al. Informant-based staging of dementia using the clinical dementia rating. Alzheimer Dis Assoc Disord 1999;13:34-7.

43 Johansson B, Zarit SH, Berg S. Changes in cognitive functioning of the oldest old. F Gerontol 1992;47:75-80

44 Ebly E, Hogan DB, Parhad IM. Cognitive impairment in the non-demented elderly: results from the Canadian study of health and aging. Arch Neurol 1995;52:612-9. 
45 Lane F, Snowdon J. Memory and dementia: a longitudinal survey of suburban elderly. In: Lovibond P, Wilson P, eds.
Clinical and abnormal psychology. Amsterdam: Elsevier, Clinical and abin

46 Koivisto K, Reinikainen KJ, Hanninen T, et al. Prevalence of age-associated memory impairment in a randomly selected population from eastern Finland. Neurology 1995;45:741-

47 Hanninen T, Koivisto K, Reinikainen KJ, et al. Prevalence of ageing-associated cognitive decline in an elderly population. Age Ageing 1996;25:201-5.

48 Christensen H, Henderson AS, Jorm AF, et al. ICD-10 mild cognitive disorder: epidemiological evidence on its validity. Psychol Med 1995;25:105-20.

49 Bennett DA, Beckett LA, Murray AM, et al. Prevalence of parkinsonian signs and associated mortality in a community population of older people. N Engl F Med 1996;334: nity pop $71-6$.

50 Morgante L, Rocca WA, Di Rosa AE, et al. Prevalence of Parkinson's disease and other types of parkinsonism: a door to door survey in three Sicilian municipalities. Neurology to door survey in

51 de Rijk MC, Breteler MMB, Graveland GA, et al. Prevalence of Parkinson's disease in the elderly: the Rotterdam study. Neurology 1995;45:2143-6.

52 Skoog I, Lernfelt B, Landahl S, et al. Fifteen year longitudinal study of blood pressure and dementia. Lance $1996 ; 347: 1141-5$.
53 Youngjohn JR, Crook TH. Stability of everyday memory in age associated memory impairment: a longitudinal study. Neuropsychology 1993;7:406-16.

54 Hanninen T, Hallikainen M, Koivisto K, et al. A follow up study of age associated memory impairment: neuropsychological predictors of dementia. 7 Am Geriatr Soc 1995;43: 1007-15.

55 Christensen H, Henderson AS, Korten AE, et al. ICD-10 mild cognitive disorder: its outcome three years later. Int $\mathcal{F}$ Geriatr Psychiatry 1997;12:581-6.

56 Ritchie K, Touchon J. Mild cognitive impairment: conceptual basis and current nosological status. Lancet 2000;355: 225-8.

57 Cooper B, Bickel H, Schaufele M. Early development and progression of dementing illness in the elderly: a general practice based study. Psychol Med 1996;26:411-9.

58 O'Connor DW, Pollitt PA, Hyde JB, et al. A follow up study of dementia diagnosed in the community using the Cambridge mental disorders of the elderly examination. Acta Psychiatr Scand 1990;81:78-82.

59 O'Connor DW, Pollitt PA, Hyde JB, et al. The progression of mild idiopathic dementia in a community population. $7 \mathrm{Am}$ mild idiopathic dementia in acc

60 Morris JC, Edland S, Clark C, et al. The consortium to establish a registry for Alzheimer's disease (CERAD). Part IV. Rates of cognitive change in the longitudinal assessment of probable Alzheimer's disease. Neurology 1993;43:245765 